\title{
RISCOS AMBIENTAIS LABORAIS NA SOCIEDADE GLOBAL E SUA PROTEÇÃO JURÍDICA
}

\author{
Carla Reita Faria Leal \\ Doutora e mestre em Direito das Relações Sociais, subárea Direito do Trabalho pela \\ Pontifícia Universidade Católica de São Paulo. Professora associada da Universidade Federal \\ de Mato Grosso, ministrando disciplinas na graduação e no mestrado em Direito. Juíza do \\ Trabalho aposentada. \\ Email: crfleal@terra.com.br
}

Solange de Holanda Rocha

Mestre em Direito Agroambiental pela Universidade Federal de Mato Grosso. Especialista em Direito Público Lato Sensu e em Direito Constitucional. Professora de Direito Constitucional, Trabalho e Previdenciário no Centro Universitário UNIC em Cuiabá/MT. Procuradora Federal em exercício na PFE/DNIT/MT. Email: solangehrocha@hotmail.com

\section{RESUMO}

A sofisticação dos riscos advindos do atual estágio do desenvolvimento industrial, combinada com a desestruturação do sistema trabalhista na sociedade global, aumenta a relevância da temática dos riscos ambientais laborais, na medida em que a prevenção de acidentes do trabalho depende do cumprimento de normas ambientais direcionadas à avaliação, controle e gestão desses riscos. Na Constituição Federal de 1988, o dever do empregador de promover a redução dos riscos inerentes ao trabalho é cumulado com o dever de arcar com o seguro obrigatório contra acidentes laborais, a cargo do seguro social, sem prejuízo da responsabilidade civil. O direito brasileiro segue a tendência de socialização dos riscos no trabalho, utilizando-se a técnica do seguro, por meio do qual é garantida uma indenização básica pela coletividade, com valores tarifados a partir da média salarial do trabalhador. A mesma lógica da tarifação da reparação foi adotada pela reforma trabalhista, ao fixar limites para indenização do dano extrapatrimonial.

Palavras-chave: Sociedade de risco. Meio ambiente do trabalho. Riscos ambientais laborais. Proteção jurídica. 


\title{
OCCUPATIONAL ENVIRONMENTAL RISKS AND THEIR LEGAL PROTECTION
}

\begin{abstract}
The sophistication of the risks arising from the current stage of industrial development combined with the dismantling of the labor system in the global society increases the relevance of the issue of occupational environmental risks, insofar as the prevention of labor accidents depends on compliance with environmental norms directed to evaluation, control and management of these risks. In the Federal Constitution of 1988, the employer's duty to promote the reduction of occupational environmental risks is cumulated with the obligation to pay compulsory insurance against labor accidents, at the expense of social insurance, without excluding civil liability. Brazilian law follows the trend of socializing labor risks, using the insurance technique, in order to guarantee a basic indemnity by the collectivity based on the average salary of the worker. The same logic of reparation pricing was adopted by the labor reform when setting limits for compensation of moral damage.
\end{abstract}

Keywords: Risk Society. Working environment. Occupational environmental risks. Legal Protection. 


\section{INTRODUÇÃO}

O tema dos riscos ganhou projeção no campo social e jurídico a partir da contribuição do sociólogo alemão Ulrich Beck, autor da obra Sociedade de Risco: rumo a uma outra modernidade, de 1986. De acordo com esse autor, a sociedade industrial, no período histórico denominado de primeira modernidade, caracterizada pela produção e distribuição de bens, pela confiança no progresso e no desenvolvimento científico-tecnológico, pela procura de pleno emprego e pelo controle da natureza, evoluiu para a sociedade de risco na fase denominada segunda modernidade, na qual o desenvolvimento da ciência e da técnica não garante o controle dos riscos ecológicos, químicos, nucleares e genéticos produzidos no estágio mais avançado das forças produtivas.

Beck defende que os cientistas sociais, diante da evolução e universalização dos riscos da modernização, devem se posicionar criticamente face às ameaças provocadas pelas ciências naturais e pelo processo de modernização, configurado e dirigido pelas forças econômicas, pela ciência e tecnologia e legitimado pelas instâncias políticas e jurídicas. Por conseguinte, as ciências naturais passam a ter importância política, na medida em que a segurança e a saúde das pessoas passam a depender de maior conhecimento sobre o cabedal de riscos inerentes às mais diversas vertentes do trabalho científico.

Tomando-se por referência alguns aspectos da teoria da sociedade de risco, notadamente quanto às consequências dos riscos gerados pela atual fase da modernidade sobre o meio ambiente e a regulação do trabalho, o presente artigo foi dividido em três partes e abordará, na primeira, o ambiente do trabalho na sociedade global de risco, na segunda, os riscos ambientais laborais com amparo na legislação brasileira e, na terceira, os fundamentos teóricos para a instituição do seguro contra acidentes de trabalho, sem prejuízo da responsabilidade civil do empregador.

$\mathrm{Na}$ perspectiva jurídica, o principal referencial para os temas abordados é a garantia constitucional de cumulação do dever imposto também ao empregador de prevenção de acidentes do trabalho, mediante redução dos riscos, por meio da observância de normas de saúde, higiene e segurança $\left[\mathrm{CF} / 88\right.$, art. $\left.7^{\circ}, \mathrm{XXII}\right]$, com o dever de arcar com o seguro obrigatório, sem excluir a responsabilidade civil [CF/88, ar. $\left.7^{\circ}, \mathrm{XXVIII}\right]$.

A metodologia utilizada foi a revisão bibliográfica, desenvolvida 
a partir da pesquisa bibliográfica orientada para a literatura especializada em âmbito nacional e internacional, tendo sido adotado o método dedutivo.

\section{MEIO AMBIENTE DO TRABALHO NA SOCIEDADE GLOBAL DE RISCO}

Entende-se por sociedade de risco o estágio da modernidade caracterizado pelas ameaças produzidas até então no caminho da sociedade industrial (BECK; GIDDENS; LASH, 1997, p. 17). Já a reflexividade da modernidade consiste no fato de que as práticas sociais são constantemente examinadas e reformadas à luz de informação renovada sobre estas próprias práticas, sendo passíveis de revisão todos os aspectos da vida humana, inclusive a intervenção tecnológica no mundo material (GIDDENS, 1991, p. 39).

No evoluir das reflexões relativas à pós-modernidade, expressão que designa um contexto sócio-histórico, que se funda na base de reflexões críticas acerca da superação dos paradigmas instituídos pela modernidade ocidental, a construção teórica acerca dos riscos foi antecedida do pensamento sobre os perigos oriundos da civilização tecnológica, expresso na obra de 1979, de Hans Jonas [1903-1993], filósofo alemão, que argumenta a favor de um dever para com a existência da humanidade futura, ou um dever de responsabilidade para com a posteridade, já que os perigos que ameaçam o futuro modo de ser são, em geral, os mesmos que, em maior escala, ameaçam a existência, por isso, evitar os primeiros significa a fortiori evitar os outros (JONAS, 2006, p. 91-92).

A distinção entre perigos e riscos é deduzida por Beck (2003, p. 113-115) do ponto de vista histórico. Sustenta que os perigos estão presentes em todas as épocas incapazes de interpretar as ameaças como condicionadas pelo homem, isto é, como condicionadas por decisões humanas. Essas ameaças são vistas como destino coletivo imposto pelas catástrofes naturais ou como castigo dos deuses etc. e, como tais, são consideradas inevitáveis. Afirma que o conceito de riscos é construído na tentativa de uma civilização de tornar previsiveis as consequências imprevisiveis das decisões tomadas, controlar o incontrolável, sujeitar os efeitos colaterais a medidas preventivas conscientes e aos arranjos institucionais apropriados.

Beck (2011, p. 49-53) alerta que muitas indústrias de risco 
foram transferidas para países com mão de obra barata. Em tais países, a exemplo de nações da Ásia e da América Latina, como Índia, Sri Lanka, Trinidade Tobago e Brasil, os regulamentos de proteção e segurança não foram suficientemente desenvolvidos. A população local, com pouca instrução, não é capaz de reconhecer e se proteger dos riscos causados pela atividade industrial dessas empresas, que, diante da falta de regulamentos de segurança, transferem, com a consciência tranquila e baixos custos, $a$ responsabilidade pelos acidentes e casos de morte à "cegueira" cultural da população em relação aos riscos. Beck conclui que, à pobreza desses países, soma-se o horror das impetuosas forças destrutivas da avançada indústria do risco, mas adverte para o que denomina de efeito bumerangue, através do qual os efeitos da pauperização dos riscos acabam contagiando os países ricos, que reimportam os alimentos baratos contaminados pelos pesticidas usados nos países periféricos.

Aponta que os problemas ambientais são - na origem e nos resultados - sociais, problemas do ser humano, de sua história, de suas condições de vida, de sua relação com o mundo e com a realidade, de sua constituição econômica, cultural e política (BECK, 2011, p. 99).

Beck (2011, p. 205-218) também aborda os efeitos das transformações em curso na sociedade sobre o sistema empregatício, dando origem ao que denomina de despadronização do trabalho assalariado, por meio de flexibilizações de três pilares de sustentação - direito do trabalho, local de trabalho e jornada de trabalho - que promovem a difusão de formas flexíveis e plurais de subemprego. A flexibilização do local e da jornada de trabalho, ao menos em alguns setores [administração, escritório, gerência, prestação de serviços], ocorre através da organização espacial do trabalho por meios eletrônicos, a exemplo do trabalho eletrônico em casa, e de forma descentralizada, difusa e independente.

Ademais, com os avanços da tecnologia da informação, mudanças sociais e jurídicas no sistema empregatício passam a ser introduzidas no direito do trabalho [contratos temporários, trabalho compartilhado, trabalho sob encomenda, trabalho de meio período, locação de trabalho], ameaçando a continuidade do sistema empregatício atual. Nesse novo cenário, adverte que os ganhos de autonomia obtidos pelos trabalhadores com a flexibilização espacial são combinados com a privatização dos riscos que o trabalho oferece à saúde física e psicológica, como abaixo transcrito: 
[...] Normas de segurança no trabalho escapam ao controle público nas formas de trabalho descentralizado e os custos por desconsiderá-las ou suspendê-las são transferidos aos trabalhadores (assim como as empresas acabam economizando os custos da organização central do trabalho assalariado, desde a manutenção das instalações até a proteção dos equipamentos eletrônicos) (BECK, 2011, p. 209).

A mudança estrutural do trabalho assalariado é consumada no seguinte processo de transição:

[...] de um sistema socioindustrial unificado de trabalho de jornada integral, vitalício, organizado de modo fabril e associado com a ameaçadora iminência do desemprego em direção a um sistema pontuado por riscos e descentralizado, de subempregos flexíveis e plurais [...] (BECK, 2011, p. 209)

Assim, revela-se um processo de erosão do antigo e, paralelamente, o processo de desenvolvimento de um novo sistema trabalhista. O sistema antigo, que se desenvolveu a partir do início do século XX, era caracterizado pela adoção de três inovações gerenciais: o emprego do taylorismo nas fábricas, modelo de administração desenvolvido pelo norte-americano Frederick Taylor, que preconiza a divisão do trabalho por tarefas, objetivando o aumento da eficiência operacional; a expansão do uso da eletricidade, com todas as suas novas possibilidades para o sistema produtivo; e o emprego de técnicas organizativas para equilibrar centralização e descentralização de grandes empresas dispersas espacialmente, de tal forma que os ganhos de produtividade potenciais $\mathrm{e}$ efetivos foram obtidos, já nessa fase inicial, por meio da racionalização de informação, tecnologia e gerenciamento organizacional (BECK, 2011, p. 213).

O novo sistema trabalhista, por sua vez, caracteriza-se por uma completa inversão da "filosofia gerencial" anteriormente válida. Isto ocorre pela substituição da mão de obra no setor industrial por equipamentos de produção automatizados, sendo as decorrentes tarefas de supervisão, direção e manutenção concentradas em poucos postos de trabalho de alto nível de qualificação técnica (BECK, 2011, p. 214).

Ao mesmo tempo, no setor da prestação de serviços, observa-se uma metamorfose das relações trabalhistas, de regimes integrais a regimes de jornada parcial. Assim, as empresas podem avaliar, de forma flexível, o volume de trabalho necessário em função das encomendas e transferir 
aos trabalhadores, sob a forma de subemprego de jornada parcial, parte dos riscos do empregador. Nesse novo sistema, as relações trabalhistas não estão pautadas na combinação de trabalho e máquina, mas na limitação temporal, na (in)segurança jurídica e na pluralização contratual do emprego de mão de obra (BECK, 2011, p. 214).

Beck (2011, p. 217) assinala não ser possível fazer qualquer prognose sobre quais setores do sistema trabalhista da sociedade industrial serão afetados por esse processo substitutivo ou quais serão poupados, mas adverte que o novo sistema de subempregos plurais e flexíveis e formas descentralizadas de trabalho, certamente, trarão ganhos de produtividade, o que lhe garante certa vantagem em relação ao sistema anterior.

Isso porque, de acordo com a perspectiva adotada em sua teoria sobre a autossubversão do sistema socioindustrial em sua fase evolutiva mais avançada, a continuidade e cesura do desenvolvimento social entrelaçam-se, condicionam-se mutuamente: continuando a prevalecer a lógica de uma racionalização orientada pelo lucro (BECK, 2011, p. 217).

Denota-se que a fase evolutiva mais adiantada do sistema socioindustrial capitalista está atrelada ao avanço do processo de globalização, daí porque também se fala em sociedade global de risco.

A globalização, de forma genérica, corresponde ao processo de intensificação das interações econômicas, sociais, políticas e culturais nas últimas três décadas.

Na definição de Santos, B.(2011, p. 11) globalização:

[...] é um processo complexo que atravessa as mais diversas áreas da vida social, da globalização dos sistemas produtivos e financeiros à revolução nas tecnologias e práticas de informação e de comunicação, da erosão do Estado nacional e redescoberta da sociedade civil ao aumento exponencial das desigualdades sociais, das grandes movimentações transfronteiriças de pessoas como emigrantes, turistas ou refugiados, ao protagonismo das empresas multinacionais e das instituições financeiras multilaterais, das novas práticas culturais e identitárias aos estilos de consumo globalizado.

Para Giddens (1991, p. 65), a globalização econômica é uma das quatro dimensões da globalização, entendida como a intensificação das relações de produção na economia capitalista mundial, sendo que as outras três dimensões envolvem a ordem militar, o sistema de Estadosnação e a divisão internacional do trabalho. Esta quarta dimensão diz 
respeito ao desenvolvimento industrial baseado em divisões de trabalho, não apenas divisões de tarefas, mas também a especialização regional em termo de tipo de indústria, capacitações e a produção de matérias-primas. Por consequência desse processo, ocorreram mudanças na distribuição mundial da produção, incluindo a desindustrialização de certas regiões nos países desenvolvidos e o surgimento dos "Países Recém-Industrializados" no Terceiro Mundo (GIDDENS, 1991, p. 70).

Giddens (1991, p.71) também alerta para os efeitos negativos da atual fase de desenvolvimento industrial sobre o meio ambiente e a saúde das pessoas, notadamente as que estão envolvidas no processo produtivo, isso porque as novas tecnologias afetam não só a produção, mas também a relação do homem com o meio ambiente laboral. Aponta que a difusão do industrialismo criou "um mundo" num sentido mais negativo e ameaçador do que o que foi mencionado - um mundo no qual há mudanças ecológicas reais ou potenciais de um tipo daninho que afeta a todos no planeta. [...]

$\mathrm{Na}$ perspectiva teórica da sociedade de risco globalizada, Bedin(2010, p. 20-21) aborda os novos riscos que afetam o meio ambiente do trabalho:

A maior flexibilidade ocorrida com os meios de produção propiciados pelo desenvolvimento da microeletrônica e das novas tecnologias de comunicação relacionados com o processo de globalização da economia também produziu efeitos sobre a saúde do trabalhador. De um lado, o trabalhador ficou exposto a uma maior variedade de produtos e condições ambientais dos processos em tempos e frequências alternados e sujeito a uma maior ocorrência de acidentes devido às mudanças frequentes de produtos e processos. Por outro lado, a comunicação do comércio internacional e sua competição criaram novas exigências, novos conceitos, novos valores e compromissos para governantes, empresas, sindicatos e consumidores em geral, criando uma consciência de preocupação e preservação do meio ambiente em todas as suas formas, inclusive o do trabalho e não mais pensando em um indivíduo de forma isolada.

A sofisticação dos riscos advindos do atual estágio do desenvolvimento industrial, combinada com a desestruturação do sistema trabalhista, aumenta a relevância da temática dos riscos ambientais laborais, a ser tratada na sequência, na medida em que a prevenção de acidentes do trabalho depende do cumprimento de normas ambientais direcionadas à avaliação, controle e gestão desses riscos. 


\section{RISCOS AMBIENTAIS LABORAIS NA LEGISLAÇÃO BRASILEIRA}

Segundo Sirvinskas (2008, p. 38), o Direito Ambiental está se transmigrando do Direito do Dano para o Direito do Risco, o que significa dizer que deve atuar mais intensamente na esfera preventiva, pois a reparação do dano nem sempre poderá reconstituir a degradação ambiental.

Na definição de Brilhante (2004, p. 39-40), o risco ambiental é o que ocorre ao meio ambiente, seja ambiente interno - no caso de uma indústria, por exemplo - ou externo, podendo ser classificado de acordo com o tipo de atividade (explosão, descarga contínua); exposição (instantânea, crônica); probabilidade de ocorrência; severidade, reversibilidade, visibilidade, duração e a ubiquidade de seus efeitos.

Brilhante (2004, p. 37-41 e 51) esclarece que eliminar todos os riscos é impossível, de tal sorte que o melhor a fazer, no primeiro momento, é a avaliação de risco, a fim de viabilizar a gestão do risco. A avaliação de risco é definida como a identificação do perigo, a localização de suas causas, a estimativa da extensão dos seus danos e a comparação destes com os benefícios. Se for possível assumir que os benefícios suplantam os riscos, para a maioria das pessoas envolvidas na atividade, considerase o risco como aceitável. Neste sentido, o autor cita como exemplo o risco inerente ao transporte aéreo, pois, tomando por base o número de voos e acidentes com vítimas por ano, a estimativa de probabilidade de um evento danoso é considerada aceitável e o meio de transporte é considerado seguro. Por outro lado, exemplifica que a fibra de asbesto ou amianto pode causar doença pulmonar fatal, afetando principalmente os trabalhadores de fábricas que utilizam tal fibra na composição de seus produtos, como telhas e freios; logo, a probabilidade anual de mortes, neste caso, ainda que seja considerada pequena, não deve ser tida como aceitável.

A gestão do risco consiste no processo que inclui seleção e implementação das medidas preventivas e protetivas mais apropriadas, tomando por base os resultados do processo de avaliação de risco, do controle tecnológico disponível, da análise de custo e benefício e custoefetividade, do risco aceitável, e preocupações com possíveis impactos ambientais.

Dentro da perspectiva dos riscos ao ambiente interno, assinala Brilhante (2004, p. 44) que proteger o meio ambiente laboral deve ser 
objetivo comum e permanente de todos os setores da empresa, contemplado no quadro de ações prioritárias e traduzido em cuidados ambientais, de saúde e de segurança ao longo de todas as operações industriais, com reflexos nas matérias-primas selecionadas, produtos, processos, instalações e práticas de trabalho.

Para alcançar tal intento, é indispensável que haja percepção dos riscos e impactos ambientais decorrentes da atividade da empresa.

Salienta-se que a Constituição Federal confere aos trabalhadores o direito à redução dos riscos inerentes ao trabalho, por meio de normas de saúde, higiene e segurança [art. $7^{\circ}$, XXII].

Por outro lado, a legislação trabalhista brasileira [CLT, art. 155] conferiu ao Ministério do Trabalho competência para estabelecer normas complementares para aplicação dos preceitos legais, o que resultou, a partir da Portaria MTb $n^{0} 3.214$, de 8 de junho de 1978, na aprovação das Normas Regulamentadoras [NRs], que foram redigidas principalmente com base nas diretrizes sobre saúde e segurança no trabalho emanadas pelas convenções da Organização Internacional do Trabalho [OIT].

Ainda nesse contexto, a NR-9 estabelece a obrigatoriedade da elaboração e implementação, por parte de todos os empregadores e instituições que admitam trabalhadores como empregados, do Programa de Prevenção de Riscos Ambientais [PPRA], visando à preservação da saúde e da integridade dos trabalhadores, através da antecipação, reconhecimento, avaliação e consequente controle da ocorrência de riscos ambientais existentes ou que venham a existir no ambiente de trabalho, tendo em consideração a proteção do meio ambiente e dos recursos naturais [item 9.1.1].

São considerados riscos ambientais laborais os agentes físicos, químicos, biológicos, ergonômicos e mecânicos existentes nos ambientes de trabalho que, em função de sua natureza, concentração ou intensidade e tempo de exposição, são capazes de causar danos à saúde do trabalhador. Em regra, a previsão dos riscos mecânicos e ergonômicos não é obrigatória no PPRA [item 9.1.5].

Os agentes fisicos consistem nas diversas formas de energia a que possam estar expostos os trabalhadores, tais como: ruídos, vibrações, pressões anormais, temperaturas extremas, radiações ionizantes, bem como o infrassom e o ultrassom [item 9.1.5.1].

Já os agentes químicos são as substâncias, compostos ou produtos que possam penetrar no organismo pela via respiratória, nas formas de 
poeiras, fumos, névoas, neblinas, gases ou vapores, ou que, pela natureza da atividade de exposição, possam ter contato ou ser absorvidos pelo organismo por meio da pele ou por ingestão [item 9.1.5.2].

São agentes biológicos as bactérias, fungos, bacilos, parasitas, protozoários, vírus, entre outros [item 9.1.5.3].

Os agentes ergonômicos estão previstos na NR-17 e consistem no conjunto de parâmetros que devem ser estudados e implantados de forma a permitir a adaptação das condições de trabalho às características psicofisiológicas dos trabalhadores, de modo a proporcionar um máximo de conforto, segurança e desempenho eficiente no ambiente de trabalho [item 17.1].

São exemplos de agentes ergonômicos: monotonia no trabalho, posição do corpo, ritmo e jornada de trabalho, trabalho repetitivo, sono, fadiga, concentração excessiva, características dos móveis e ferramentas, conflitos, entre outros. Os agentes ergonômicos podem gerar distúrbios psicológicos e fisiológicos e provocar sérios danos à saúde do trabalhador porque produzem alterações no organismo e no estado emocional, comprometendo sua produtividade, saúde e segurança. A aplicação dos conhecimentos de ergonomia permite o necessário ajustamento entre o homem e as condições de trabalho sob os aspectos de praticidade, conforto físico e psíquico.

Os agentes mecânicos se originam das atividades mecânicas, envolvendo máquinas e equipamentos responsáveis pelo surgimento de lesões nos trabalhadores quando da ocorrência dos acidentes de trabalho. Os riscos mecânicos são muito diversificados e podem estar presentes em ferramentas e equipamentos defeituosos, máquinas sem proteção, movimentação ou armazenamento impróprio de máquinas ou materiais, materiais aquecidos [que provocam queimaduras], materiais perfurocortantes [que provocam cortes], materiais ou instalações energizadas [que provocam choques], entre outros.

Ainda no tocante à NR-9, esta dispõe que as ações do PPRA devem ser desenvolvidas no âmbito de cada estabelecimento da empresa, sob a responsabilidade do empregador, com a participação dos trabalhadores, sendo sua abrangência e profundidade dependentes das características dos riscos e das necessidades de controle [item 9.1.2].

OPPRAé parte integrante do conjunto mais amplo de iniciativas da empresa para preservação da saúde e da integridade física dos trabalhadores, devendo estar articulado com o disposto nas demais NRs[item 9.1.3], em 
especial com a NR-4, que trata do Serviço Especializado em Engenharia de Segurança e em Medicina do Trabalho [SESMT], com a NR-5, que dispõe sobre a Comissão Interna de Prevenção de Acidentes [CIPA] e com a NR7, que institui o Programa de Controle Médico de Saúde Ocupacional [PCMSO], mecanismos estes voltados à promoção da saúde e proteção da integridade física dos trabalhadores.

$\mathrm{Na}$ elaboração e desenvolvimento das ações de prevenção em saúde e segurança no trabalho, as referidas NRs devem ser cumpridas de forma integrada. A NR-4 especifica o dimensionamento do pessoal técnico. A NR-5 dimensiona a representação dos trabalhadores no processo de gestão de riscos laborais, por meio da CIPA. A NR-7 focaliza a aptidão dos trabalhadores em face dos riscos nos ambientes de trabalho. A NR-9 traça as normas para elaboração e implementação do PPRA, que integra todos os dados coletados nas demais NRs do grupo.

Os programas ambientais específicos para determinadas atividades econômicas, que envolvem maior risco e altos índices de acidentes, também devem ser elaborados e implementados em articulação com as NRs citadas, a exemplo do Programa de Condições e Meio Ambiente de Trabalho na Indústria da Construção - PCMAT [NR18, item 18.3.1.1] e o PPRA de empresas frigoríficas de abate e processamento de carnes e derivados [NR-36, item 36.11.6, letra $b$ ], que também deve observar as normas de ergonomia da NR-17 [item 36.12.1].

A elaboração, implementação, acompanhamento e avaliação do PPRA poderão ser feitos pelo SESMT ou por pessoa ou equipe de pessoas que, a critério do empregador, sejam capazes de desenvolver o disposto na NR-9 [item 9.3.1.1].

Compete ao empregador estabelecer, implementar e garantir o cumprimento do PPRA como atividade permanente da empresa ou instituição [item e 9.4.1].

Sobre a responsabilidade do empregador, como principal mantenedor do meio ambiente do trabalho, explica Zimmermann (2012, p. 75-76):

Aos empregadores incumbe a detecção e a avaliação dos riscos decorrentes do desenvolvimento de suas atividades, sejam inerentes, sejam adquiridos pelo modo de produção escolhido; as atuações preventiva e cautelar voltadas ao tratamento dos riscos; a implementação de equipamentos de proteção coletiva (EPCs) e o 
fornecimento, em último caso, de EPIs com a devida orientação e fiscalização da sua efetiva utilização pelos empregadores; a informação aos trabalhadores acerca dos riscos a que estão expostos e o treinamento para o desenvolvimento da atividade de modo a reduzir os riscos e, por último, a programação de medidas de urgência para serem utilizadas diante de eventual ocorrência de danos individuais ou coletivos.

Ao traçar a distinção entre riscos ambientais laborais inerentes e adquiridos, a autora assevera que todas as atividades profissionais geram algum risco, sendo alguns mais acentuados que outros. As atividades enquadradas como tipicamente perigosas, a exemplo daquelas que impliquem contato permanente com inflamáveis, explosivos ou energia elétrica, contêm riscos inerentes, que devem ser reduzidos aos limites permitidos pelo atual estágio da técnica, somente isentando o mantenedor do ambiente de trabalho dos prejuizos pessoais, materiais e sociais decorrentes da atividade quando efetivamente comprovado o cumprimento do dever de segurança (ZIMMERMANN, 2012, 98).

Entretanto, a forma como o trabalho é exercido, normalmente determinada pelo empreendedor, pode incrementar os riscos inerentes ou, até mesmo criar outros riscos, que são os riscos adquiridos pela atividade, cujos danos decorrentes são de inteira responsabilidade de quem os criou, como ocorre, por exemplo, na utilização de agrotóxicos na agricultura, uma vez que tal atividade poderia ser exercida sem contato do trabalhador com agentes químicos (ZIMMERMANN, 2012, 98-99).

Já os trabalhadores podem e devem colaborar e participar da implantação e execução do PPRA, apresentando propostas, recebendo informações e orientações dos riscos ambientais presentes, incluindo os dados consignados no Mapa de Riscos, que é confeccionado pela CIPA após ouvir os trabalhadores de todos os setores produtivos, sob a orientação do SESMT e seguindo as orientações contidas Anexo IV da NR-5. Devem, ainda, seguir as orientações recebidas nos treinamentos oferecidos pelo programa e se reportarem ao seu superior hierárquico direto as ocorrências que, a seu julgamento, possam implicar risco a sua saúde [itens 9.4.2, 9.5.1, 9.5.2, 9.6.1 e 9.6.2].

$\mathrm{Na}$ ocorrência de evento que importe em situação de grave e iminente risco no ambiente de trabalho, o empregador deve garantir aos trabalhadores que interrompam de imediato suas atividades, comunicando o fato ao superior hierárquico direto para as devidas providências [item 
9.6.3].

Ao abordar a redução dos riscos inerentes ao trabalho, Oliveira (2010, p. 121) esclarece que existe a redução desejável [eliminação] e a redução aceitável [neutralização], sendo que o primeiro propósito é a redução máxima, por meio da eliminação do agente prejudicial. Todavia, quando isso for inviável tecnicamente, o empregador terá de, pelo menos, reduzir a intensidade do agente prejudicial para o território das agressões toleráveis.

Neste sentido, o autor cita o item 4.12 da NR-4, que dispõe sobre o dever dos profissionais integrantes do SESMT, no sentido de aplicar seus conhecimentos ao ambiente de trabalho e a todos os seus componentes, inclusive máquinas e equipamentos, de modo a reduzir até eliminar os riscos ali existentes à saúde do trabalhador $\mathrm{e}$, quando a eliminação não for possível e o risco persistir, determinar a utilização, pelo trabalhador, de equipamentos de proteção individual (EPI), de acordo com o que determina a NR-6, desde que a concentração, a intensidade ou característica do agente assim o exija (OLIVEIRA, 2010, p. 121).

Persistindo os riscos, a atividade pode ser caracterizada como insalubre, em razão da exposição dos trabalhadores a agentes nocivos à saúde, acima dos limites de tolerância fixados em razão da natureza e da intensidade do agente e do tempo de exposição aos seus efeitos [CLT, art. 189].

ANR-15, que prevêo enquadramentodas atividades caracterizadas como insalubres, define como limite de tolerância aos agentes agressivos a concentração ou intensidade máxima ou mínima, relacionada com a natureza e o tempo de exposição ao agente, que não causará dano à saúde do trabalhador, durante a sua vida laboral [item 15.1.5].

Oliveira (2010, 122-123) adverte que estudos científicos divulgados por organismos internacionais, como a Organização Internacional do Trabalho e a Organização Mundial da Saúde, têm demonstrado que os limites de tolerância, até então tidos como aceitáveis, provocam danos à saúde do trabalhador, a longo prazo. Isso ocorre, notadamente, quando considerados os aspectos relacionados à duração da jornada, que no Brasil é ordinariamente extrapolada, enquanto os limites de tolerância são estabelecidos com base em uma jornada normal de oito horas e à presença, em regra, de vários agentes nocivos simultaneamente, vez que os limites fixados observam apenas um agente agressivo de forma isolada, deixando de observar as Convenções n. 148 e n. 155 da OIT no 
particular.

Para evitar que as exposições a agentes ambientais ultrapassem os limites de tolerância, a NR-9 define um nível de ação, a partir do qual devem ser iniciadas ações preventivas que incluem o monitoramento periódico da exposição, a informação aos trabalhadores e o controle médico [item 9.3.6.1]. O nível de ação deve ser determinado pelos profissionais do SESMT, por meio da definição do cronograma e dos métodos de intervenção nos ambientes de trabalho para controle dos riscos, o que caracteriza a efetiva gestão dos riscos ambientais.

Como dito, a proteção do meio ambiente laboral depende da percepção dos riscos e impactos ambientais decorrentes da atividade da empresa. Até o momento, foram abordados os riscos e, com vistas ao fechamento da segunda parte deste artigo, falar-se-á, sucintamente, do estudo de impacto ambiental e respectivo relatório de impacto ao meio ambiente, conhecidos pelas abreviações EIA/RIMA.

O EIA/RIMA é um importante instrumento de política ambiental destinado a identificar e avaliar os impactos e degradações ambientais tanto na fase de implantação como na operação da atividade ou obra. É obrigatório para a instalação de obra ou atividade potencialmente causadora de impacto ambiental, como determina a Constituição Federal [art. 225, § $1^{\circ}$, IV], a Lei 6.938/81 [art. 9 , III] e Resolução n ${ }^{\circ}$ 01/86 do Conselho Nacional do Meio Ambiente [art. 5, II].

O EIA/RIMA é elaborado por uma equipe multidisciplinar, em função da necessidade de considerar os impactos ambientais da atividade sobre os diversos aspectos do meio ambiente: natureza, patrimônio cultural, patrimônio histórico e o meio ambiente do trabalho.

Entretanto, ainda é pouco utilizado no âmbito trabalhista, mas deveria ser incentivado e perquirido pelas autoridades competentes do Ministério do Trabalho e Emprego, como forma de se prevenir efetivamente os riscos ambientais e os consequentes danos à saúde e integridade física dos trabalhadores (MELO, 2006, p.79).

Neste sentido, a legislação brasileira estabelece que o início das atividades da empresa deve ser submetido à prévia inspeção e aprovação das respectivas instalações pela fiscalização do MTE, o que, certamente, poderia contribuir para prevenção de acidentes de trabalho e de doenças ocupacionais [CLT, art. $160, \S \S 1^{\circ}$ e $2^{\circ}$ ].

Portanto, a elaboração do EIA/RIMA também deve contemplar a participação dos trabalhadores, que fornecerão informações adequadas 
das condições ambientais de trabalho, visando prevenir os impactos das atividades potencialmente degradadoras sobre sua saúde ou integridade física.

Não sendo eficaz a prevenção dos riscos e ocorrendo o dano, mesmo com todos os mecanismos colocados à disposição de empregadores e empregados pelo ordenamento jurídico brasileiro, necessário se faz a sua reparação, tema que será discutido a seguir.

\section{RESPONSABILIDADE ACIDENTÁRIA DO SEGURADOR PÚBLICO E RESPONSABILIDADE CIVIL DO EMPREGADOR NO DIREITO BRASILEIRO}

Em oposição ao risco, principalmente os ambientes de risco que afetam coletivamente os indivíduos, Giddens (1991, p.37) apresenta o conceito de segurança como uma situação na qual um conjunto especifico de perigos está neutralizado ou minimizado. Para este autor, a experiência de segurança baseia-se geralmente num equilíbrio de confiança e risco aceitável, sendo este entendido como o risco conscientemente calculado, o qual é variável em diferentes contextos, e pode se referir a grandes coletividades de pessoas ou até incluir a segurança global.

Na seara jurídica, Cavalieri Filho (2012, p. 155-156), ao abordar a responsabilidade objetiva baseada na teoria do risco, adverte que ninguém responde por coisa alguma só porque exerce atividade de risco, muitas vezes até socialmente necessária. A responsabilidade decorre da violação de um dever jurídico, que será, normalmente, o dever de segurança que a lei estabelece, implícita ou explicitamente, para quem cria risco para outrem. Risco e segurança são fatores que atuam reciprocamente na vida moderna, cuja atividade primordial é driblar riscos. Onde há risco tem que haver segurança e quanto maior o risco, maior será o dever de segurança. Assim, de um lado, a ordem jurídica garante a liberdade de ação e a livre iniciativa e, de outro, garante a proteção do ser humano, conferindo-lhe o direito subjetivo à segurança.

Segundo Cavalieri Filho(2012, p. 165-167), a tendência de socialização dos riscos no trabalho vem se acentuando, nas últimas décadas, em razão do aumento do número de acidentes, tornando, muitas vezes, irreparável o dano, não só pelo montante da indenização, mas, também, pela falta de patrimônio da parte que o causou. Assim, por meio do que a doutrina denomina de reparação coletiva, indenização autônoma ou social, 
garante-se uma indenização básica para qualquer tipo de acidente pessoal. $O$ dano, por esse novo enfoque, deixa de ser apenas contra a vítima para ser contra a própria coletividade, passando a ser um problema de toda a sociedade. Para alcançar a socialização do dano, utiliza-se a técnica do seguro, porquanto se consegue, através dele, distribuir os riscos entre todos os segurados, para que a reparação dos danos seja garantida pela coletividade, através de um seguro coletivo, a cargo dos empregadores, pelo qual se transfere ao segurador o encargo de pagar a indenização.

Para Beck (2003, p. 115-116), um caso de acidente de trabalho, com base nas interpretações propostas pelos sociólogos a partir do século XIX e no começo do século XX, em oposição à ideologia liberalista dependente do mercado, não deve ser visto como infortúnio a ser suportado pelo indivíduo isoladamente, mas deve ser considerado como fato social. Logo, compete às instituições jurídicas e políticas darem respostas à questão da causalidade mediante compensação financeira pelos danos oriundos do acidente e distribuição das responsabilidades.

Nesta toada, Beck (2003, p. 117-118) fala sobre a instituição do seguro estatal de acidentes para dar cobertura aos trabalhadores, face aos riscos gerados pela atividade industrial, tal como ocorreu na Alemanha a partir da lei de Bismarck, no século XIX. Aponta que é essencial que o seguro seja implementado, pois constitui-se instrumento para a criação da ordem interna do Estado nacional, o qual tem a tarefa de intermediar os conflitos, institucionalizando a distribuição das consequências e dos custos na prevenção dos riscos entre os membros da sociedade. Segundo o autor, somente após esta institucionalização foi possível a deflagração de um otimismo desenvolvimentista. Isso porque só diante do pano de fundo do fato de que os efeitos colaterais sempre seriam de algum modo compensados por um programa institucionalizado é que esse otimismo pôde se disseminar e, assim, acelerar o progresso.

Em objeção ao projeto delineado no seguro estatal, ressalta-se a impossibilidade de controlar os efeitos colaterais gerados pela progressiva radicalização dos processos de industrialização, entendidos como riscos associados a determinados fatos sociais causadores de problemas ambientais, cujas consequências não são espacial, temporal e socialmente delimitáveis, que erodem e põem em questão justamente esse programa institucionalizado de cálculo dos efeitos colaterais (BECK, 2003, p. 118119).

No contexto histórico das relações sociais e econômicas 
intensificadas pelo processo de globalização, ganha força a ideia de instituição e manutenção do sistema securitário contra infortúnios laborais com fundamento na teoria do risco social. Costa (2013, p. 52) propugna que a globalização fez com que se passasse a admitir o compartilhamento de responsabilidades entre diferentes seguimentos sociais e produtivos, já que, além do autor da lesão, a sociedade também se aproveita dos bens e riquezas resultantes do processo de produção, devendo suportar um sistema que ampare aqueles que são vítimas, resultando na passagem do risco individual para o coletivo, face ao caráter social de que se reveste o infortúnio.É a chamada socialização dos riscos, que conduz à cobertura dos infortúnios laborais através do seguro social.

O ordenamento jurídico brasileiro aderiu à ideia do seguro social, estabelecendo que a responsabilidade do segurador público, em matéria acidentária, será sempre objetiva, com supedâneo no art. $7^{\circ}$, XXVIII, da Constituição Federal.

Isto significa que o pagamento ou disponibilização da prestação acidentária [serviço ou benefício] pelo Instituto Nacional do Seguro Social [INSS] ocorre independentemente de análise acerca da presença ou não de riscos ambientais laborais ou da existência de culpa ou dolo do empregador ou da empresa diante dos fatos, bastando a comprovação do infortúnio, do seu nexo causal com o trabalho desenvolvido, do dano decorrente e da condição de beneficiário (segurado ou dependente) junto à previdência social (ZIMMERMANN, 2012, p. 115).

Sendo assim, o seguro acidentário é caracterizado pela responsabilidade objetiva coletiva, fundada na teoria do risco social, assegurando que a vítima seja indenizada, mesmo se o causador do dano não puder ser individualizado, refletindo a aplicação da teoria do risco integral, segundo a qual o dever de indenizar se faz presente, ainda nos casos de culpa exclusiva da vítima, fato de terceiro, caso fortuito ou força maior.

De fato, sob a égide da Constituição Federal, a disciplina normativa do Seguro de Acidente do Trabalho ou Riscos Ambientais do Trabalho [SAT/RAT] está contida nas Leis $\mathrm{n}^{\circ} 8.212$ e 8213, de 24 de julho de 1991, que instituíram, respectivamente, o plano de custeio e de benefícios do Regime Geral de Previdência Social. As referidas leis foram regulamentadas pelo Decreto $n^{\circ} 3048 / 99$, que aprovou o Regulamento da Previdência Social.

No magistério de Sette (2005, p. 217), a Lei $n^{\circ} 8.213 / 91$ 
adotou quanto a acidentes de trabalho a teoria do seguro social, que é fundamentada na solidariedade social e no fenômeno da socialização dos riscos.

O custeio é imputado à empresa ou empregador, aí incluído o empregador doméstico, assim como pelos tomadores da mão de obra avulsa e pelos segurados especiais, por meio do recolhimento mensal da contribuição social destinada ao SAT/RAT, com vistas a cobrir os custos com o pagamento das prestações acidentárias.

Na lição de Santos, M. (2008, p. 147), inspirada no princípio da repartição dos riscos, a Lei $n$. 8213/91 adotou o princípio da reparação tarifada, limitando-se ao pagamento dos efeitos patrimoniais do dano pessoal.

Na concepção deste autor (SANTOS, opus cit., 2008, 132-137), ao equiparar o benefício acidentário ao previdenciário, sem levar em conta a extensão do dano em cada caso, o regime de acidentes do trabalho incorporou fundamentos do direito assistencial, mediante a transferência da responsabilidade e dos custos dos acidentes de trabalho provocados pelo risco da empresa para toda a coletividade, agravando a crise de autonomia do regime acidentário, que foi diluído no sistema de seguridade social.

Entretanto, o seguro contra acidentes de trabalho não exonera o empregador da reparação civil, como expressamente previsto no art. 121 da Lei $n^{0} 8.213 / 91$. Neste caso, a reparação é fixada com base no instituto jurídico da responsabilidade civil, como leciona Oliveira (2011, p.77):

\footnotetext{
Onde houver dano ou prejuízo, a responsabilidade civil é invocada para fundamentar a pretensão de ressarcimento por parte daquele que sofreu as consequências do infortúnio. É, por isso, instrumento de manutenção da harmonia social, na medida em que socorre o que foi lesado, utilizando-se do patrimônio do causador do dano para restauração do equilíbrio rompido. Com isso, além de punir o desvio de conduta e amparar a vítima, serve para desestimular o violador potencial, o qual pode antever e até mensurar o peso da reposição que seu ato ou omissão poderá acarretar.
}

Antes da atual Constituição, a Súmula 229 do Supremo Tribunal Federal [STF] assim enunciava: $A$ indenização acidentária não exclui a do Direito Comum, em caso de dolo ou culpa grave do empregador. A exigência de dolo ou culpa grave prevista na súmula foi superada pelo inciso XXVIII do art. $7^{\circ}$ do caderno constitucional, que se refere à indenização a que o empregador está obrigado, quando incorrer em dolo ou culpa. Com 
fundamento nessa norma, parte da doutrina admite a responsabilidade subjetiva do empregador pelo acidente de trabalho, desde que provado que agiu com qualquer parcela de culpa, ainda que leve, contribuindo para a ocorrência do acidente.

Há também corrente doutrinária que advoga a responsabilidade objetiva do empregador, com fundamento no art. $225, \S 3^{\circ}$, da $\mathrm{CF} / 88 \mathrm{e}$ art. $14, \S 1^{\circ}$, da Lei $6.938 / 81$, pois, sendo o meio ambiente do trabalho um aspecto integrante do meio ambiente geral, os acidentes decorrentes de desequilíbrios ambientais ou condições ambientais de trabalho inseguras atraem as regras da responsabilidade objetiva.

Uma terceira corrente sustenta a responsabilidade objetiva depois da vigência do Código Civil de 2002, com supedâneo no art. 927, parágrafo único, aplicável ao acidente causado pelo exercício de atividade de risco, que corresponde ao risco excepcional ou acentuado a que são submetidos trabalhadores que exercem atividades insalubres ou perigosas, com fundamento na teoria do risco profissional, ou em outras teorias como a do risco proveito ou do risco criado.

De acordo com a teoria do risco proveito, o responsável pela reparação do dano é aquele que tira algum proveito ou vantagem do fato lesivo. Cavalieri Filho (2012, p. 153) adverte que a grande dificuldade, nesta teoria, está na identificação do proveito, pois, se proveito tiver sentido de lucro ou vantagem econômica, a responsabilidade fica restrita aos comerciantes e industriais, não sendo aplicável aos casos em que a coisa causadora do dano não é fonte de ganho.

Cavalieri Filho (2012, p. 154) também aborda a teoria do risco criado, na qual a reparação do dano decorre do exercício de atividade ou profissão que cria um perigo para os indivíduos. Apoiado na doutrina de Caio Mário, afirma que o traço distintivo entre as duas teorias é que no risco criado o dever de reparação resulta da atividade em si mesma, independentemente do resultado bom ou mau que dela advenha para o agente.

Quanto à incorporação da regra da responsabilidade objetiva no Código Civil de 2002, destaca Gschwendtner (2006, p. 113) que relevante flexibilização da subjetividade, trazida às claras pelo Código de 2002, confere ao juiz certa discricionariedade para a avaliação do risco envolvido na atividade e, com isso, da especifica incidência da regra objetivista.

Ao traçar a distinção entre a reparação infortunística prestada 
pelo segurador público e a indenização decorrente da responsabilização do empregador, esclarece Dallegrave Neto (2008, p. 232):

Ao nosso crivo, a distinção também se dá no fato do INSS cobrir todos os acidentes de trabalho indistintamente, vez que o foco é não deixar o segurado desprotegido, notadamente nos infortúnios decorrentes de fatalidades em que não há qualquer culpa patronal. Havendo culpa do empregador ou no caso de acidente oriundo de atividade em que o risco é previsível da própria atividade normal da empresa, o agente deverá indenizar a vítima sem qualquer compensação com o valor de benefício, além do benefício previdenciário. Sim, pois, do contrário, o simples custeio mensal do SAT eximiria o empregador de qualquer indenização, abrindo espaço espúrio de incentivo ao descumprimento das normas de medicina e segurança do trabalho, o que é inadmissível, sobretudo num país recordista mundial de acidente do trabalho.

Cavalieri Filho (2012, p. 167, apud MONTENEGRO, 1992, p. 367-368), também se manifesta no sentido de compatibilizar a reparação do seguro social com a indenização devida, em caso de responsabilização individual; isso porque a cumulação corresponde melhor aos ideais de uma justiça comutativa, quando configurado fique o dolo do lesante ou quando aquela indenização se mostre insuficiente para cobrir todo o dano suportado pela vítima.

Theodoro Junior (1989, p. 169-170), sob a perspectiva históricoevolutiva, analisa a concorrência da responsabilidade acidentária atribuída ao segurador público com a responsabilidade civil do empregador:

A evolução do direito acidentário se deu, historicamente, à base de uma nítida separação de terrenos entre a responsabilidade civil comum e a responsabilidade oriunda do risco do trabalho.

À medida que se ampliava ao extremo o risco específico do trabalho, outorgando ao operário e à sua família a maior garantia possível, passava-se, de outro lado, a proteger, de forma diversa, também o empregador, pois este, após o cumprimento do seguro obrigatório, ficava liberado de qualquer outra responsabilidade pelo mesmo evento, com o que se preservavam empresa e sua incolumidade econômica, diante de riscos, às vezes exagerados e insuportáveis.

Com isso, o espírito das leis que, ao longo da história, acobertaram o risco do trabalho, se manifestou no rumo de evitar a acumulação das ações de indenização acidentária com as de responsabilidade civil acidentária.

No entanto, as leis existem para a vida, e não a vida para as leis. Logo, o direito 
positivo sentiu-se na necessidade de amoldar-se à realidade da vida, deixando de lado o purismo de estruturas que se mostram sólidas e perfeitas apenas na elaboração doutrinária, mas que, na prática, se ressentem de deficiências inevitáveis e, portanto, intoleráveis.

À vista disso e para que o seguro obrigatório não se transformasse no incentivo ao aumento do risco específico do trabalho, provocado pelo desleixo do patrão com as medidas de segurança indispensáveis, e até mesmo para coibir o dolo ou a má-fé do empregador, surgiram dispositivos especiais prevendo a exclusão, do campo da infortunística, de danos gerados pela falta intencional ou inescusável.

Vale registrar que a orientação jurisprudencial no sentido de admitir a cumulação dos benefícios acidentários com a indenização por responsabilidade civil do empregador foi construída ao longo de várias décadas na Justiça Comum. Com o advento da EC n ${ }^{\circ}$ 45/2004 e posterior pronunciamento do STF no julgamento do conflito de competência $\mathrm{n}^{\circ}$ 7.204, em 29 de junho de 2005, foi de vez reconhecida a competência da Justiça do Trabalho para julgar as ações de indenização por acidente do trabalho em face ao empregador.

A transposição da competência suscitou controvérsias na esfera justrabalhista de questões que já estavam pacificadas na jurisprudência, como, por exemplo, o cabimento da compensação dos valores pagos pelo INSS na indenização devida pelo empregador, o que rapidamente também ficou superado, prevalecendo o posicionamento de que o seguro acidentário protege a vítima e seus dependentes, sem substituir a obrigação do empregador na reparação do dano causado, obrigações que possuem fatos geradores diversos.

Santos, M. (2008, p. 139) opõe-se à combinação dos sistemas de seguro social e responsabilidade civil para acumulação de indenizações [CF/88, art. $\left.7^{\circ}, \mathrm{XXVIII}\right]$, somada ao dever de prevenção de acidentes $\left[\mathrm{CF} / 88\right.$, art. $\left.7^{\circ}, \mathrm{XXII}\right]$, sustentando ser preciso reconstruir um novo paradigma que garanta autonomia ao regime especial de acidentes do trabalho, sob o impulso da teoria do risco da empresa, descartando a teoria do risco social. Para o autor, o pensamento dominante - em favor da coincidência de regimes do cúmulo das indenizações - deve ser afastado, pois não resiste às interpretações logicossistemática e teleológica.

É fato que a doutrina majoritária e jurisprudência dominante na Justiça do Trabalho caminharam no sentido de admitir a cumulação de indenizações, notadamente pela falta de vocação indenizatória das 
prestações contempladas no seguro social, como se extrai da lição de Simm (2005, p. 105-106):

\begin{abstract}
Releva notar que a seguridade social não tem natureza ou finalidade indenizatória, no sentido de ressarcir ou compensar um dano sofrido pelo indivíduo, mas, sim, de proporcionar-lhe meios de satisfazer as necessidades resultantes de eventos próprios da vida, dando-lhe a necessária (ao menos a mínima) cobertura para fazer frente às vicissitudes da vida, de cobrir os chamados "riscos sociais", quais sejam, os acontecimentos imprevisíveis, ao menos inevitáveis, que venham a colocá-lo em estado de necessidade.
\end{abstract}

Sobre o assunto, veja-se a posição de Santos, M. (2008, p. 148):

Por outro lado, a tarifação do dano, típica dos sistemas de Seguridade Social, é necessária para viabilizar o seu pagamento por meio do seguro social. Todavia, o valor da compensação tarifada dos danos pessoais garantido pelo SAT deveria ser calculado a partir de critérios atuariais que o aproximem da reparação integral, incluindo-se também os danos extrapatrimoniais, morais, estéticos e despesas com tratamento de saúde.

É claro que o sistema tarifado nunca poderá se ajustar ao caso concreto do mesmo modo como se procede na liquidação judicial, em que o juiz tem a faculdade de ajustar a indenização mediante critérios de equidade. Mesmo assim, essa possibilidade de a técnica atuarial aproximar o valor do benefício à reparação integral satisfaz as exigências de internalização dos custos de atividade ao mesmo tempo em que garante ao trabalhador uma indenização mais digna.

É interessante observar que a recente reforma promovida na CLT, por meio da Lei $\mathrm{n}^{\circ} 13.467 / 2017$, e posteriormente através da MP 808, de efêmera vigência, introduziu a técnica da tarifação à reparação dos danos extrapatrimoniais trabalhistas. Desse modo, se interpretada de forma literal, o que não é o melhor caminho e técnica, prevalecerá o entendimento de que não mais se aplica a faculdade do juiz de ajustar a indenização devida no caso concreto mediante critérios de equidade, como mencionado na lição acima citada, devendo o juízo fixar a indenização a ser paga, a cada um dos ofendidos, aplicando os parâmetros estabelecidos 
no art. $223-\mathrm{G}, \S 1^{\circ}$, I a IV, da CLT, que oscilam entre 3 e 50 vezes o valor do último salário contratual do ofendido, conforme a ofensa varie da natureza leve a gravíssima. Na hipótese de a ofensa ser dirigida ao empregador, a indenização será calculada com os mesmos parâmetros, mas observandose o salário contratual do ofensor.

A tarifação criou tratamento anti-isonômico para casos em que trabalhadores com funções e remunerações diferentes sejam vítimas de um mesmo evento danoso, permitindo uma reparação que deixa a centralidade da pessoa humana e foque em sua renda. Por outro lado, o dispositivo em questão também vai ao encontro do artigo $5^{\circ}$, V, da Constituição Federal, que elege o critério da proporcionalidade nas reparações por danos materiais e extrapatrimoniais.

$\mathrm{Na}$ visão da doutrina civilista (ROSENVALD, 2018), é grave a falha do legislador trabalhista ao impor uma tabela para a indenização do dano extrapatrimonial, como se lê:

[...] Se, para muitos, o tabelamento seria elogiável em termos de segurança jurídica, temos que compreender que no século XXI, segurança jurídica não mais significa a exclusiva tutela da conservação de situações patrimoniais, porém, a sua adequação com a garantia de acesso a direitos fundamentais, dentre os quais podemos incluir a vedação de categorias apriorísticas que reduzem uma infinidade de comportamentos antijurídicos a meros preços tabelados, o que não apenas "coisifica" o ser humano, como, especificamente na reforma da CLT, permite que o empregador possa antecipadamente calcular o valor da lesão a direitos da personalidade e "internalizálos" no processo produtivo. A MP 808/17 alterou a referida parametrização, substituindo o critério remuneratório da vítima para limites máximos atrelados a múltiplos dos benefícios do Regime Geral de Previdência Social. Contudo, persiste a crítica quanto ao "aprisionamento" dos valores reparatórios e as suas deletérias consequências.

Importante consignar, ainda, que no sistema jurídico vigente, além da indenização devida ao trabalhador, o empregador também pode ser responsabilizado, na via de regresso, perante o seguro social, como se extrai da contribuição de Zimmermann (2012, p. 116).

Assim, é a relação segurador-segurado que está coberta pela responsabilidade objetiva, já que este deve ter a vida facilitada, considerando que, quando busca aquele para obter um beneficio, encontra-se em situação de fragilidade. Tal 
responsabilidade coletiva objetiva assumida pelo segurador frente ao segurado, entretanto, não representa isenção de responsabilidade do causador do dano quando este for devidamente identificado. Pelo contrário: em prol de toda a coletividade, que arca com a carga da indenização da vítima, o agente do dano deve responder pelo ilícito causado ou pelo risco criado que foi indevidamente suportado pelo trabalhador.

Para responsabilizar o causador do dano perante a coletividade, o INSS deve manejar o instrumento processual conhecido como ação regressiva acidentária, com fundamento no artigo 120 da Lei $\mathrm{n}^{\circ}$ 8.213/91.

Percebe-se, assim, que a reparação prestada pelo seguro acidentário não afasta a responsabilidade individual do causador do dano, frente ao trabalhador e ao próprio segurador público, nas hipóteses albergadas na legislação e admitidas pela doutrina e jurisprudência pátria.

\section{CONSIDERAÇÕES FINAIS}

No atual estágio da modernidade, os fatores de risco no trabalho são constantemente alterados pelo avanço tecnológico e novas técnicas de divisão do trabalho. Ao mesmo tempo, revela-se um processo de erosão do sistema trabalhista e assalariado da sociedade industrial e o desenvolvimento de um novo sistema de subempregos plurais e flexíveis e formas descentralizadas de trabalho.

A globalização, de forma genérica, corresponde ao processo de intensificação das interações econômicas, sociais, políticas e culturais nas últimas três décadas. É resultado da consolidação do modelo econômico capitalista, aliada ao estabelecimento de um sistema mundial de comunicações e ao desenvolvimento tecnológico, que promoveram uma nova organização do mercado mundial e uma nova divisão internacional do trabalho.

No direito brasileiro, a Constituição Federal de 1988 conferiu aos trabalhadores urbanos e rurais, além de outros que visem à melhoria de sua condição social, os direitos à redução dos riscos inerentes ao trabalho, por meio de normas de saúde, higiene e segurança [art. $\left.7^{\circ}, \mathrm{XXII}\right]$ e ao seguro contra acidentes de trabalho, a cargo do empregador, sem excluir a indenização a que este está obrigado, quando incorrer em dolo ou culpa [art. $7^{\circ}$, XXVIII].

Há, portanto, o dever de prevenção de acidentes combinado com 
um regime de seguro obrigatório e responsabilidade civil, conduzindo à interpretação de que o custeio do SAT/RAT não exime o empregador de qualquer indenização, principalmente quando demonstrado que o acidente foi ocasionado pelo descumprimento de medidas de saúde e segurança no ambiente de trabalho.

O regime financeiro adotado na Previdência Social é baseado na repartição simples, o que significa que o pagamento de benefícios acidentários é repartido por toda a sociedade. Teoricamente, os sistemas públicos são considerados os mais aptos a conferir proteção social adequada aos trabalhadores, pois foram concebidos à luz do princípio do seguro coletivo, através do qual os riscos de infortúnios e suas consequências são distribuídos entre os membros da sociedade.

O seguro social brasileiro concede uma indenização básica, pois o único benefício indenizatório previsto no regime, o auxílio-acidente, é de caráter continuado e fixado em percentual único sobre a média de salários do trabalhador. Daí porque a cobertura previdenciária não exclui a responsabilidade civil do empregador; todavia, a reparação civil por dano extrapatrimonial recentemente passou a ser tabelada pela novel legislação trabalhista, o que não se mostra a opção mais acertada, pois, se interpretada de forma literal, afastará a possibilidade de o juiz fixar a indenização observando os critérios de equidade em cada caso que se apresente.

No contexto da reforma trabalhista, é importante trazer a lume a discussão acerca do aprimoramento da cobertura acidentária no âmbito do SAT/RAT, o que é possível de ser alcançado, desde que seja dado um tratamento jurídico diferenciado ao risco ocupacional, que dispõe de fonte de custeio específica, em relação aos demais riscos sociais cobertos pela previdência social, para que os custos advindos dos sinistros laborais sejam integralmente cobertos pelos causadores dos danos e não repartidos por toda a sociedade.

\section{REFERENCIAS}

BECK, Ulrich. Liberdade ou Capitalismo: Ulrich Beck conversa com Johannes Willms. Tradução de Luiz Antônio Oliveira de Araújo. São Paulo: Unesp, 2003.

BECK, Ulrich. Sociedade de risco: rumo a uma outra modernidade. Tradução de Sebastião Nascimento. 2. ed. São Paulo: Editora 34, 2011. 
BECK, Ulrich; GIDDENS, Anthony; LASH, Scott. Modernização reflexiva: política, tradição e estética na ordem social moderna. Tradução de Magda Lopes. São Paulo: Editora Unesp, 1997.

BEDIN, Barbara. Prevenção de Acidentes de Trabalho no Brasil sob a ótica dos incentivos econômicos. São Paulo: LTr, 2010.

BRILHANTE, Ogenis Magno. Gestão e Avaliação da Poluição, Impacto e Risco em Saúde Ambiental. In: BRILHANTE, Ogenis Magno; CALDAS, Luiz Querino de A. [org.]. Gestão e Avaliação de Risco em Saúde Ambiental. 2. reimp. Rio de Janeiro: Editora Fiocruz, 2004.

CAVALIERI FILHO, Sergio. Programa de Responsabilidade Civil. 10 ed. São Paulo: Atlas, 2012.

COSTA, Hertz Jacinto. Manual de Acidente do Trabalho. 7. ed. Curitiba: Juruá, 2013.

DALLEGRAVE NETO, José Affonso. Responsabilidade Civil no Direito do Trabalho. 3. ed. São Paulo: LTr, 2008.

GIDDENS, Anthony. As consequências da modernidade. 5. ed. Tradução de Raul Fiker. São Paulo: Editora Unesp, 1991.

GSCHWENDTNER, Loacir. A constitucionalização do direito privado contemporâneo. Florianópolis: OAB/SC Editora, 2006.

JONAS, Hans. O princípio responsabilidade: Ensaio de uma ética para a civilização tecnológica. Tradução de Das PrinzipVerantwortung. Rio de Janeiro: Contraponto: Ed. PUC-Rio, 2006.

MELO, Raimundo Simão de. Direito Ambiental do trabalho e a saúde do trabalhador: responsabilidades legais, dano material, dano moral, dano estético, indenização pela perda de uma chance, prescrição. 2. ed. São Paulo: LTr, 2006.

OLIVEIRA, Sebastião Geraldo de. Proteção Jurídica à Saúde do Trabalhador. 5ed. São Paulo: LTr, 2010.

OLIVEIRA, Sebastião Geraldo de. Indenizações por acidente do trabalho ou doença ocupacional. São Paulo: LTr, 2011. 
ROSENVALD, Nelson. O novo dano moral trabalhista - Um ensaio sobre a cegueira (do legislador). Disponível em: https://www.nelsonrosenvald. info/single-post/2017/12/05/O-novo-dano-moral-trabalhista$\% \mathrm{E} 2 \% 80 \% 93-U m$-ensaio-sobre-a-cegueira-do-legislador. Acesso em: 10 mar. 2018.

SANTOS, Boaventura de Sousa. Os processos de globalização. In: SANTOS, Boaventura de Sousa [org.]. A Globalização e as Ciências Sociais. 4. ed. São Paulo: Cortez, 2011.

SANTOS, Marco FridolinSommer. Acidente do Trabalho entre a seguridade social e a responsabilidade civil: elementos para uma teoria do bem-estar e da justiça social. 2 ed. São Paulo: LTr, 2008.

SETTE, André Luiz Menezes Azevedo. Direito Previdenciário Avançado. 2 ed. Belo Horizonte: Mandamentos, 2005.

SIMM, Zeno. Os direitos fundamentais e a seguridade social. São Paulo: LTr, 2005.

SIRVINSKAS, Luís Paulo. Manual de Direito Ambiental. 6. ed. São Paulo: Saraiva, 2008.

THEODORO JUNIOR, Humberto. Acidente do trabalho na nova constituição. Revista da Faculdade de Direito da UFMG, 1989, p. 165-177. ZIMMERMAN, Cirlene Luiza. A Ação Regressiva Acidentária como Instrumento de Tutela no Meio Ambiente de Trabalho. São Paulo: LTr, 2012.

\section{Como citar este artigo (ABNT):}

LEAL, Carla Reita Faria; ROCHA, Solange de Holanda. RISCOS AMBIENTAIS LABORAIS NA SOCIEDADE GLOBAL E SUA PROTEÇÃO JURÍDICA. Veredas do Direito, Belo Horizonte, v. 15, n. 33, p. 263-290, set./dez. 2018. Disponível em: <http://www.domhelder. edu.br/revista/index.php/veredas/article/view/1351>. Acesso em: dia mês. ano.

Artigo recebido em: 07/09/2018

Artigo aceito em: 20/11/2018 